\title{
Correction to: atypical radiological findings of primary central nervous system lymphoma
}

Xuling Lin ${ }^{1}$ - Iram Rais Alam Khan ${ }^{2} \cdot$ Ying Hao Christopher Seet ${ }^{1} \cdot$ Hwei Yee Lee ${ }^{3} \cdot$ Seyed Ehsan Saffari ${ }^{4} \cdot$ Wai-Yung Yu $^{2}$

Published online: 25 March 2020

(C) Springer-Verlag GmbH Germany, part of Springer Nature 2020

Correction to: Neuroradiology (2020).

https://doi.org/10.1007/s00234-020-02377-0

The above article was published with incorrect list of authors. We have added Seyed Ehasan Saffari and his affiliation as the addition of the new author to the author list was requested at revision stage. All authors agreed to the new author list and the Editor-in-Chief approved this change.

The online version of the original article can be found at https://oi.org/ $10.1007 / \mathrm{s} 00234-020-02377-0$

\section{Xuling Lin}

lin.xu.ling@singhealth.com.sg

1 Department of Neurology, National Neuroscience Institute, 11 Jalan, Tan Tock Seng, Singapore 308433, Singapore

2 Department of Neuroradiology, National Neuroscience Institute, Singapore, Singapore

3 Department of Pathology, Tan Tock Seng Hospital, Singapore, Singapore

4 Health Services and Systems Research, Duke-Nus Medical School, Singapore, Singapore 